\title{
Superação de dormência em sementes de Senna spectabilis (DC) H. S. Irwin \&
}

\section{Barneby}

Overcoming dormancy in Senna spectabilis (DC) H. S. Irwin \& Barneby seeds

Superar la latencia en Senna spectabilis (DC) H. S. Irwin \& Barneby Seeds

Jessia Elem Cunha Barbosa

ORCID: https://orcid.org/0000-0002-5783-9670

Universidade Estadual de Alagoas, Brasil

E-mail: jessia19@hotmail.com

Abel Barbosa Lira Neto

ORCID: https://orcid.org/0000-0001-7597-3761

Universidade Estadual de Alagoas, Brasil

E-mail: abel.neto@uneal.edu.br

Daniel de Souza Santos

ORCID: https://orcid.org/0000-0001-6230-2985

Universidade Estadual de Alagoas, Brasil

E-mail: daniel.biologo14@gmail.com

Esmeralda Aparecida Porto Lopes

ORCID: https://orcid.org/0000-0003-3765-0712

Universidade Estadual de Alagoas, Brasil

E-mail: esmeralda.porto@uneal.edu.br

Gabrielle de Lima Mendes

ORCID: https://orcid.org/0000-0003-3767-4503

Universidade Estadual de Alagoas, Brasil

E-mail: gabriellemendes1998@gmail.com

Giselle Silva de Souza

ORCID: https://orcid.org/0000-0003-2598-4205 Universidade Estadual de Alagoas, Brasil

E-mail: giselle.silva908@gmail.com

João Lucas Cavalcante Santos

ORCID: https://orcid.org/0000-0003-4360-9943 Universidade Estadual de Alagoas, Brasil

E-mail: joao.lucas.c1707@gmail.com

Jhonatan David dos Santos das Neves

ORCID: https://orcid.org/0000-0003-1558-6430

SMED/ Casa da Ciência e Planetário, Brasil

E-mail: jhonataneducador@yahoo.com.br

Leonardo da Silva Santos

ORCID: https://orcid.org/0000-0003-2617-436X Universidade Estadual de Alagoas, Brasil

E-mail: leossantos.bio@gmail.com

Millena Duarte Costa

ORCID: https://orcid.org/0000-0003-0141-7353 Universidade Estadual de Alagoas, Brasil

E-mail: millenad414@gmail.com

Rubens Pessoa de Barros

ORCID: https://orcid.org/0000-0003-0140-1570 Universidade Estadual de Alagoas, Brasil

E-mail: pessoa.rubens@gmail.com

Stephany Flávia Mendoça de Araujo

ORCID: https://orcid.org/0000-0003-1696-6224 Universidade Estadual de Alagoas, Brasil E-mail: stephanyflavia@hotmail.com

Tamara da Nascimento Xavier

ORCID: https://orcid.org/0000-0003-0442-2959

Universidade Estadual de Alagoas, Brasil

E-mail: tamaraxaaviier27@gmail.com

Thaíse da Silva Santos

ORCID: https://orcid.org/0000-0002-0208-651X

Universidade Estadual de Alagoas, Brasil

E-mail: thaisedasilvasantos@gmail.com 


\title{
Resumo
}

A Senna spectabilis (Fabaceae-Caesalpinioideae) é uma espécie arbórea que ocorre no norte de Minas Gerais e Nordeste brasileiro, presente em formações de caatinga com solos profundos e drenados. Possui importância econômica como madeireira, medicina caseira, planta ornamental, restauração florestal, sistemas agroflorestais e forrageira. $\mathrm{O}$ estudo objetivou-se conhecer o efeito dos Microrganismos Eficientes (EM) em diferentes diluições na quebra de dormência na germinação de sementes da Senna spectabilis. Para a execução do trabalho os frutos foram coletados no Bosque das Arapiracas, em Arapiraca, e em seguida foram levados para o Laboratório de Recursos Florestais no Polo Tecnológico Agroalimentar, onde realizou-se o teste de germinação. O experimento foi realizado em delineamento inteiramente casualizado -DIC feito em quatro tratamentos e 5 repetições. Onde T1 é o controle/testemunha com 100\% de água destilada; T2 - com 2\% de bokashi+ água destilada; T3 - com 3\% de bokashi + água destilada e T4 - com 4\% de bokashi + água destilada. Após os tratamentos as sementes foram colocadas para germinar em câmara de germinação (BOD). Os dados foram coletados e registrados em uma planilha do Excel para análise de IE e IVE. As sementes de S. spectabilis semeadas em bokashi a $4 \%$ obtiveram um bom índice de germinação e de velocidade de germinação. O tratamento que obteve melhor resultado foi o T4, seguido pelo T2 e o Tratamento 3 com bokashi a 3\% teve o maior índice de morte das sementes. O experimento confirmou que é possível quebrar a dormência das sementes utilizando método de quebra com EM.

Palavras-chave: Germinação; Senna; Microrganismos eficientes.

\begin{abstract}
Senna spectabilis (Fabaceae-Caesalpinioideae) is a tree species that occurs in northern Minas Gerais and northeastern Brazil, present in caatinga formations with deep and drained soils. It has economic importance as timber, home medicine, ornamental plants, forest restoration, agroforestry and forage systems. The study aimed to understand the effect of Efficient Microorganisms (EM) at different dilutions in breaking dormancy in the germination of Senna spectabilis seeds. To carry out the work, the fruits were collected at Bosque das Arapiracas, in Arapiraca, and then taken to the Forest Resources Laboratory at the Agrifood Technology Pole, where the germination test was carried out. The experiment was carried out in a completely randomized design -DIC carried out in four treatments and 5 replications. Where $\mathrm{T} 1$ is the control/control with $100 \%$ distilled water; $\mathrm{T} 2$ - with $2 \%$ bokashi+ distilled water; T3 with $3 \%$ bokashi + distilled water and $\mathrm{T} 4$ - with $4 \%$ bokashi + distilled water. After the treatments, the seeds were placed to germinate in a germination chamber (BOD). Data were collected and recorded in an Excel spreadsheet for analysis of IE and IVE. Seeds of S. spectabilis sown in $4 \%$ bokashi had a good germination index and germination speed. The treatment that obtained the best result was T4, followed by T2 and Treatment 3 with $3 \%$ bokashi had the highest seed death rate. The experiment confirmed that it is possible to break seed dormancy using the EM break method.
\end{abstract}

Keywords: Germination; Senna; Efficient microorganisms.

\section{Resumen}

Senna spectabilis (Fabaceae-Caesalpinioideae) es una especie arbórea que se encuentra en el norte de Minas Gerais y noreste de Brasil, presente en formaciones de caatinga con suelos profundos y drenados. Tiene importancia económica como madera, medicina casera, plantas ornamentales, restauración forestal, agroforestería y sistemas forrajeros. El estudio tuvo como objetivo comprender el efecto de los microorganismos eficientes (EM) a diferentes diluciones en la ruptura de la latencia en la germinación de semillas de Senna spectabilis. Para realizar el trabajo, los frutos se recolectaron en el Bosque das Arapiracas, en Arapiraca, y luego se llevaron al Laboratorio de Recursos Forestales del Polo de Tecnología Agroalimentaria, donde se realizó la prueba de germinación. El experimento se realizó en un diseño completamente al azar -DIC realizado en cuatro tratamientos y 5 repeticiones. Donde T1 es el control / control con $100 \%$ de agua destilada; T2 - con $2 \%$ de bokashi + agua destilada; T3 - con 3\% de bokashi + agua destilada y T4 con $4 \%$ de bokashi + agua destilada. Después de los tratamientos, las semillas se colocaron para germinar en una cámara de germinación (DBO). Los datos se recopilaron y registraron en una hoja de cálculo de Excel para el análisis de IE e IVE. Las semillas de S. spectabilis sembradas en $4 \%$ de bokashi tuvieron un buen índice de germinación y velocidad de germinación. El tratamiento que obtuvo el mejor resultado fue el T4, seguido del T2 y el Tratamiento 3 con bokashi al 3\% tuvo la mayor tasa de muerte de semillas. El experimento confirmó que es posible romper la latencia de las semillas utilizando el método de ruptura EM.

Palabras clave: Germinación; Senna; Microorganismos eficientes. 


\section{Introdução}

Espécimes de Senna spectabilis são empregadas no Brasil principalmente no paisagismo, devido à grande beleza das suas flores amarelas, sendo uma espécie com grande potencial para recomposição de áreas degradadas. A S. spectabilis ocorre em duas variedades distintas principalmente pelo porte: Senna spectabilis (DC) Irwin \& Barneby var. spectabilis (Cassia spectabilis DC.), conhecida como Cassia Carnaval, árvore de grande porte (até $17 \mathrm{~m}$ ) e Senna spectabilis (DC) Irwin \& Barneby var. excelsa (Schrad.) Irwin e Barneby (Cassia excelsa Schrad), de pequeno porte (até $6 \mathrm{~m}$ ) conhecida como cássiado-nordeste (Silva, et al., 2010).

Segundo Siqueira e Siqueira (2013), o bokashi é uma mistura balanceada de matérias orgânicas de origem vegetal e/ou animal, submetidas a processo de fermentação controlada. Por ser tão versátil existem inúmeras receitas disponíveis em várias fontes, porém é importante ressaltar que a alma do processo está na capacidade fermentativa dos Microrganismos Eficientes (EMs) nativos. Esta reação do metabolismo destes organismos garantem a decomposição da matéria orgânica adicionada ao meio e libera no solo os nutrientes em formas menos tóxicas, e disponíveis para a utilização das plantas (Aragão et al., 2020).

De acordo com Moreira e Malavolta (2004), a dormência das sementes é um dos principais problemas para produção de mudas de espécies florestais nativas, principalmente de leguminosas. Em espécies florestais nativas é comum a presença de sementes que, mesmo viáveis, não germinam, embora as condições ambientais estejam aparentemente favoráveis. Estas sementes são consideradas dormentes e podem necessitar tratamento especial para germinar, as dormências podem ser do tipo física, morfológica e fisiológica. (Albuquerque et al., 2007).

Existem diferentes tipos de tratamentos e técnicas para desativar (quebrar) a dormência nas sementes, que vai depender do tipo de dormência e outros fatores a serem analisados. Entre os tratamentos utilizados com sucesso para quebra da dormência de espécies florestais, destacam-se as escarificações mecânica e química, além da imersão das sementes em água quente ou em outras substâncias ou microrganismos. A aplicação e a eficiência desses tratamentos dependem do grau de dormência, que é variável entre diferentes espécies, procedências e anos de coleta (Oliveira et al., 2003).

Partindo da hipótese que uso de Microrganismos Eficientes (EM) podem ser eficazes na quebra de dormência das sementes de Senna spectabilis, o artigo teve como objetivo conhecer o efeito dos Microrganismos Eficientes (EM) em diferentes diluições na quebra de dormência na germinação de sementes da Senna spectabilis.

\section{Metodologia}

\section{Local da pesquisa}

A pesquisa foi desenvolvida no Polo Tecnológico Agroalimentar de Arapiraca, Sítio Bananeiras, zona rural do município de Arapiraca - Alagoas ( $09^{\circ} 45^{\prime} 09^{\prime \prime} \mathrm{S}, 36^{\circ} 39^{\prime} 40^{\prime \prime} \mathrm{W}$ ) (Figura 1). O município de Arapiraca é o segundo maior e mais importante do interior do estado de Alagoas. O clima da região é do tipo As', determinando o clima tropical e quente segundo a classificação de (Köppen \& Geiger ,1928). Este município apresenta uma altitude média em torno dos 250 metros e se encontra em uma região de transição dos biomas Mata Atlântica e Caatinga, do sertão semiárido. Por isso, tal região é denominada popularmente de "Agreste" (Xavier \& Dornellas, 2012). 
Figura 1. Localização do Polo Agroalimentar de Arapiraca.

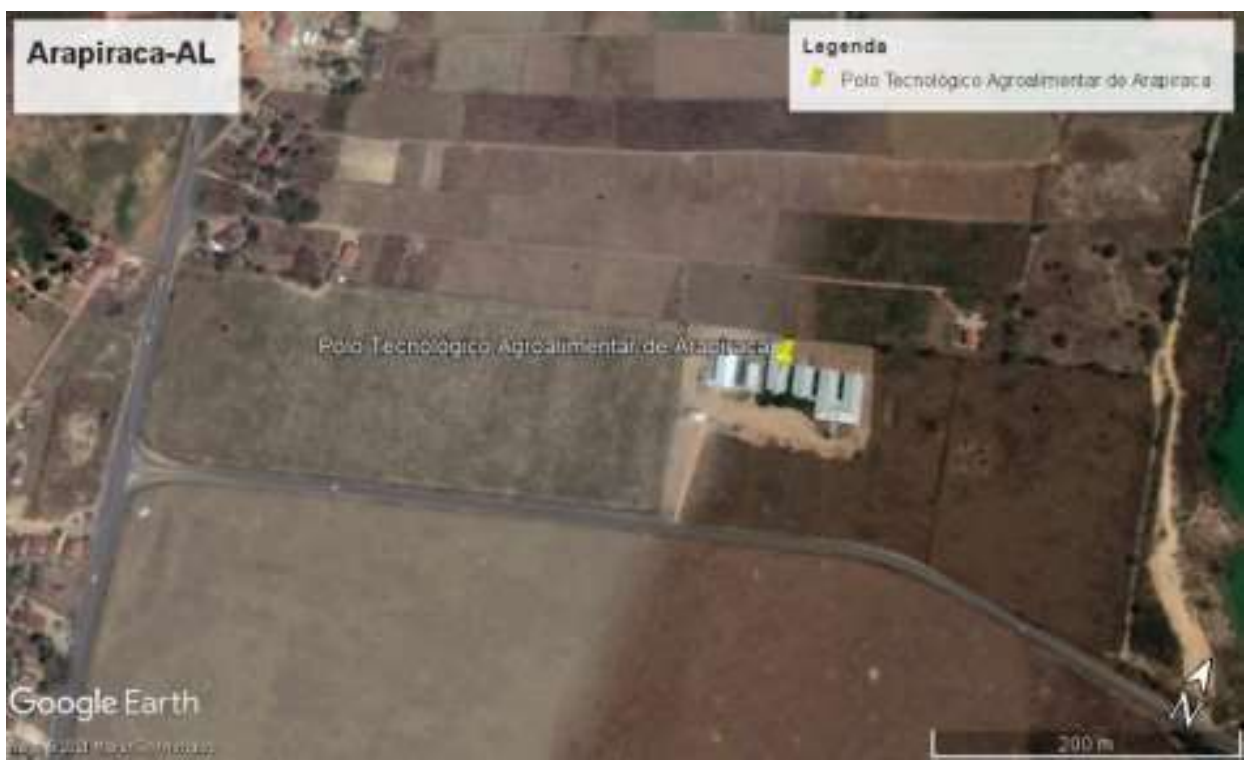

Fonte: Acervo dos autores (2021).

\section{Procedimentos metodológicos}

Trata-se de um estudo experimental, feito em laboratório e para o teste de germinação foi utilizado a adaptação do método (BRASIL, 2009). Utilizou-se um total de 400 sementes para o experimento (100 em cada tratamento), para obtenção das sementes os frutos foram coletados no Bosque das Arapiraca, em Arapiraca, no mês de Setembro.

Após serem coletados e separados, os frutos foram levados para o Laboratório de Recursos Florestais no Polo Tecnológico Agroalimentar, onde foi realizado o processo de retirada da semente dos frutos, as sementes foram selecionadas, removendo as que apresentavam algum defeito ou algum sinal de predação, a fim de se obter um lote de sementes homogêneo seguindo a técnica de (Araujo et al., 2019; Leite et al., 2021).

Foi feito a assepsia dos utensílios utilizados, bancada e sementes, essa última foi desinfetada com hipoclorito de sódio $(\mathrm{NaClO})$ a $2 \%$, por cerca de 1 minuto e lavada com agua destilada, posteriormente colocadas para secar em temperatura ambiente sobre o papel toalha.

O experimento foi realizado em delineamento inteiramente casualizado -DIC feito em quatro tratamentos e 5 repetições. Onde T1 é o controle/testemunha com 100\% de água destilada; T2 - com 2\% de bokashi+ água destilada; T3 com 3\% de bokashi + água destilada e T4 - com 4\% de bokashi + água destilada. Para diluição do Bokashi usou-se água destilada e bokashi nas proporções de $2 \%, 3 \%$ e $4 \%$ (Figura 2). 
Figura 2. Diluições do Bokashi a 2\%, $3 \%$ e $4 \%$ e água destilada.



Fonte: Acervo dos autores (2021).

Para o teste de germinação, utilizou-se 12 papeis toalhas para cada amostra; onde estes foram auto clavados e pesados, o peso foi multiplicado por 2,5 -3,0 para se obter o volume de solução que foi umidificado o papel. Em cada repetição foi semeada 20 sementes, dispostas em 2 folhas de papel toalha já umedecidos com as soluções referente a cada tratamento e enroladas.

As amostras foram identificadas com número do tratamento e número de repetição. Posteriormente as amostras em formas de rolos, foram dispostas em sequência e colocadas na câmara de germinação BOD (Biological Oxygen Demand) em condições e luminosidade estabelecidas nas RAS -Regra de Análise de Sementes (Brasil, 2009) (Figura 3).

Figura 3. Amostras identificadas e organizadas em badeja de polietileno na BOD.

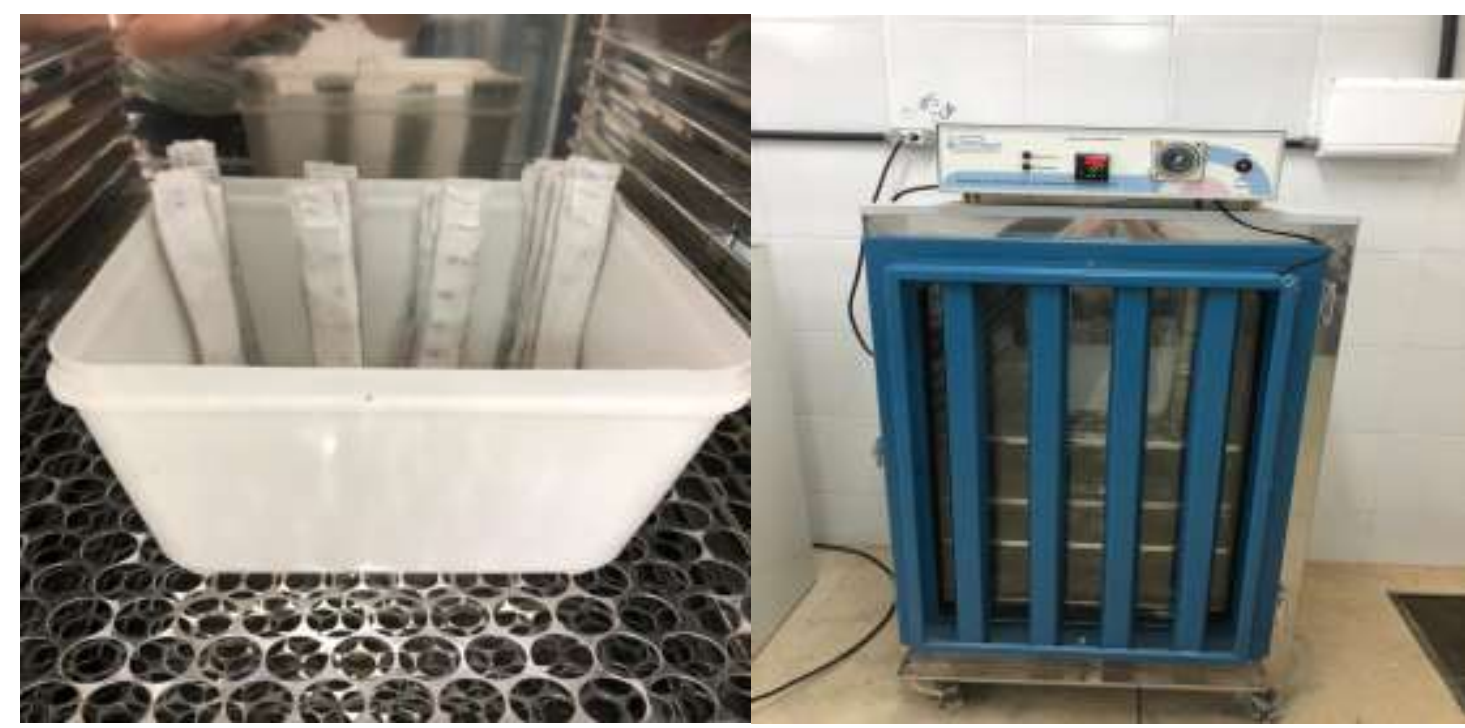

Fonte: Acervo dos autores (2021).

Na primeira contagem de germinação, foi registrada a porcentagem de plântulas normais, plântulas anormais, sementes mortas e sementes dormentes verificadas sete dias após a instalação do ensaio, foram consideradas 
emergidas/germinadas as sementes que apresentaram emissão de radícula (Figura 4), a segunda contagem foi realizada aos 14 dias após, a instalação do ensaio cujos resultados foram expressos nos gráficos dos resultados.

Figura 4: Primeira contagem das sementes emergidas.

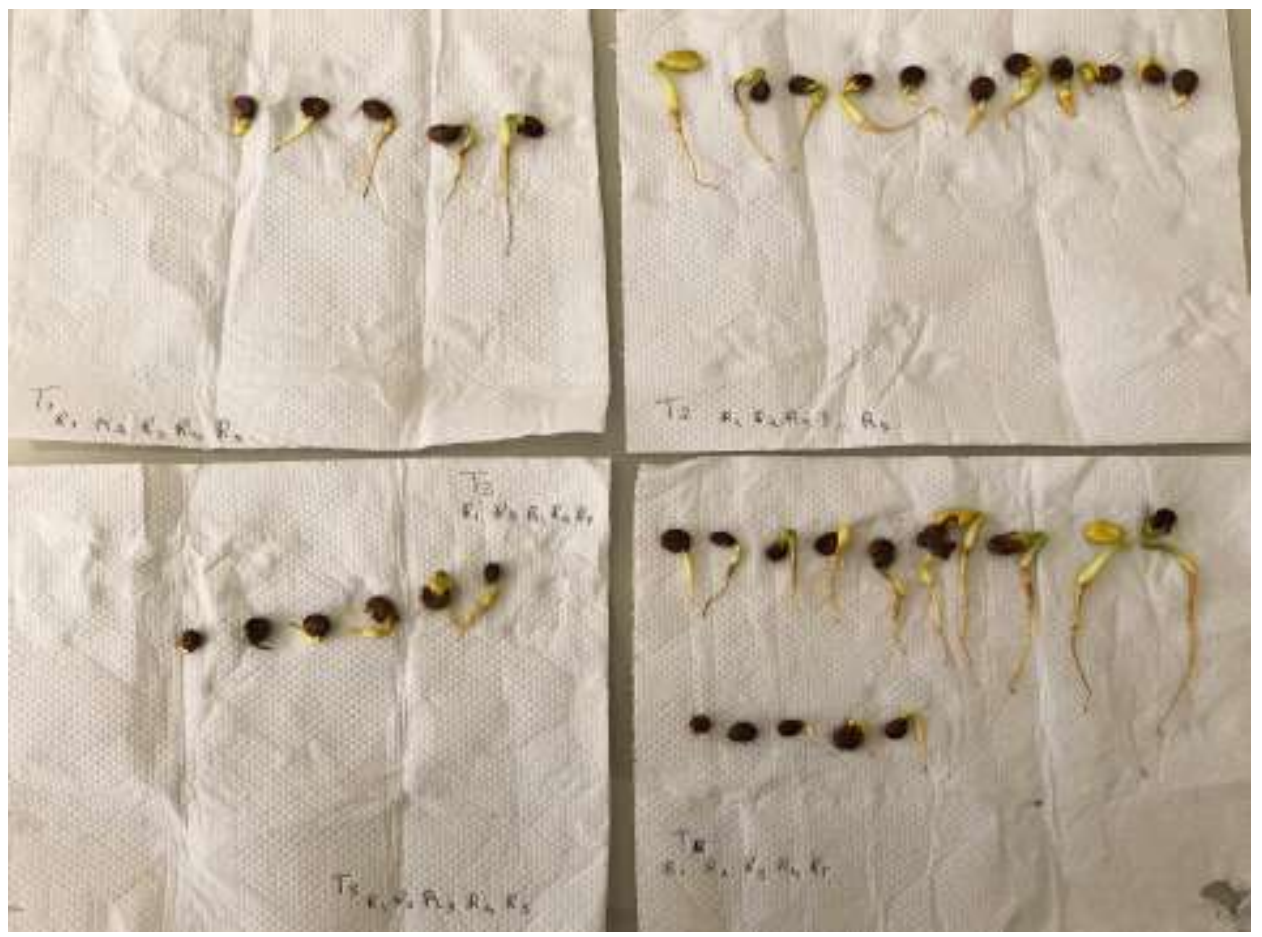

Fonte: Acervo dos autores (2021).

\section{Análise dos dados}

Ao iniciar as germinações os dados foram coletados e registrados em uma planilha do Excel para análise de IE (índice de Emergência) (1) e IVE (índice de velocidade de Emergência) (2) onde foram utilizadas as seguintes fórmulas:

$$
\mathrm{IE}=\frac{E \cdot 100 \%}{N}(1)
$$

Em que: $\mathrm{E}=$ número total de plântulas germinadas, $\mathrm{e} \mathrm{N}=$ número total de sementes.

$$
\mathrm{IVE}=\frac{\mathrm{E} 1}{\mathrm{~N} 1}+\frac{\mathrm{E} 2}{\mathrm{~N} 2}+\cdots \frac{\mathrm{En}}{\mathrm{Nn}}
$$

Em que: $E_{1}, E_{2}$ e $E_{n}=$ número de plântulas na primeira, na segunda e na última contagem, e $\mathrm{N}_{1}, \mathrm{~N}_{2}$ e $\mathrm{N}_{3}=$ número de dias após a semeadura na primeira, na segunda e na última contagem.

$\mathrm{O}$ registro dos dados foi feito semanalmente sendo tabelados em planilhas do Excel para posteriormente serem analisados estatisticamente, através do programa Agroestat (Maldonado JR., 2021) para verificar a ANOVA-análise de variância e a comparação de médias através do teste de Tukey a 5\% de probabilidade. 


\section{Resultados e Discussão}

Após a análise dos dados foi possível constatar que houve significância no que se refere aos dias de avaliação da germinação. O método de quebra de dormência testado com EMs se assemelha com escarificação química, devido ao pH ácido do bokashi, o percentual de acidez pH do bokashi foi de 2,94 identificado com pHmetro. Os resultados de Nunes et al. (2006), mostram que os métodos de escarificação têm tido sucesso na superação de dormência $S$. spectabilis que atuaram como um acelerador do processo germinativo nesta espécie.

Das diluições todas apresentaram superioridade ao tratamento testemunha, dentre as diluições os resultados mais promissores foi T4, apresentando superioridade em relação aos demais tratamentos, como mostra na Tabela 1.

Tabela 1. Média da porcentagem de sementes emergidas (\% E) e Índice de velocidade de emergência (IVE) das sementes sob efeito das diluições do bokashi em diferentes dias de avaliação.

\begin{tabular}{cccc}
\hline Tratamentos & \multicolumn{2}{c}{ Dias de avaliações (\%E) } & IVE* \\
\cline { 2 - 3 } Testemunha & 7 & 14 & \\
Bokashi 2\% & $1,00 \mathrm{~b}$ & $1,40 \mathrm{~b}$ & $0,17 \mathrm{c}$ \\
Bokashi 3\% & $2,40 \mathrm{ab}$ & $2,80 \mathrm{ab}$ & $0,35 \mathrm{ab}$ \\
Bokashi 4\% & $1,20 \mathrm{~b}$ & $2,20 \mathrm{ab}$ & $0,24 \mathrm{~b}$ \\
Média & $3,00 \mathrm{a}$ & $3,00 \mathrm{a}$ & $0,42 \mathrm{a}$ \\
\hline CV\% & $\mathbf{1 , 8 5}$ & $\mathbf{2 , 3 5}$ & $\mathbf{0 , 2 9}$ \\
\hline
\end{tabular}

As médias seguidas por a mesma letra minúscula não se diferem pelo teste de Tukey a 5\% de probabilidade de erro. *IVE aos 14 dias. Fonte: Dados da pesquisa.

Conforme o índice de determinação $\left(\mathrm{R}^{2}\right)$, para o IE foi de $\mathrm{R}^{2}=0,125$ no $\mathrm{T} 1$ e para o $\mathrm{T} 4$ o $\mathrm{R} 2=0,81$, infere-se que os Microrganismo Eficientes utilizados em diferentes proporções influenciou no IE e IVE nas sementes da espécie estudada, pois as germinações aumentaram significativamente em relação ao Tratamento Testemunha (T1) esse último teve o pior índice de germinação, que pode ser um reflexo da ausência de microrganismos, pois só foi utilizado água destilada nas sementes esterilizadas nesse tratamento (Figuras 5 e 6), divergindo dos resultados de Morpeth \& Hall (2000), onde nesse estudo só com desinfestação das sementes de Ochroma e água destilada obteve superação da dormência e não havendo aceleração nos tratamentos com EM. 
Figura 5. Índice de Emergência individual dos tratamentos T1 e T4.

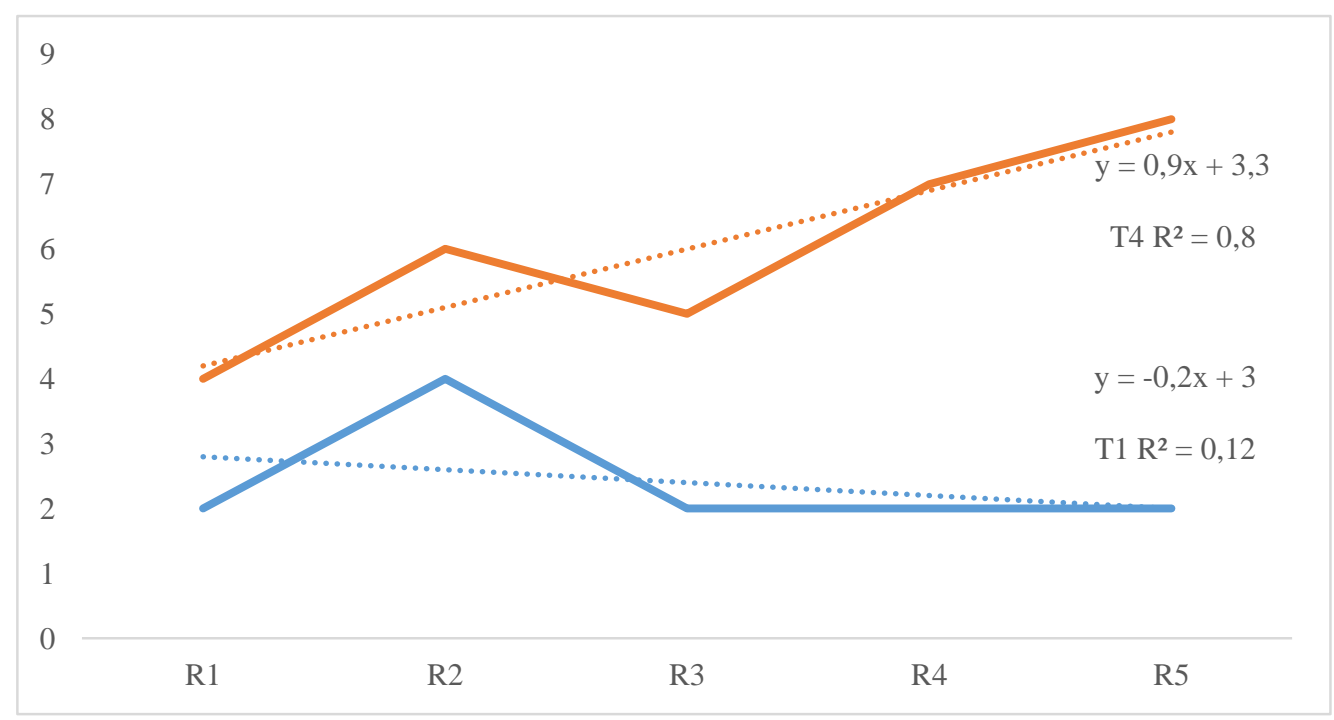

Fonte: Dados da pesquisa.

Figura 6. Índice de Velocidade de Emergência dos Tratamentos T1, T2, T3 e T4.

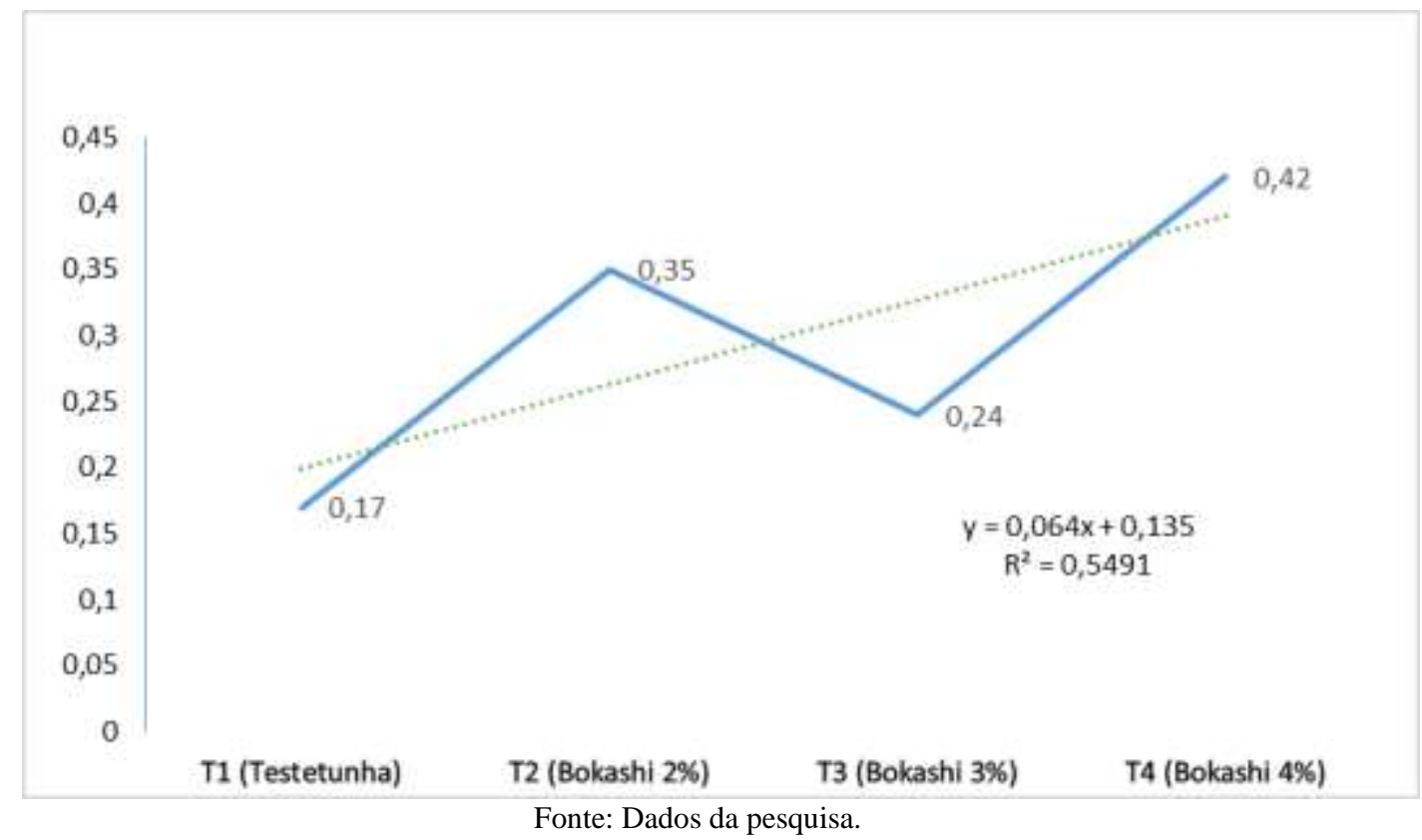

De forma geral, houve uma tendência dos maiores valores de porcentagem de germinação estarem associados às maiores médias de velocidades de germinação. Este mesmo comportamento foi observado por Munhoz et al. (2009); Santos et al. (2021).

Com a inoculação de microrganismos em Rosa damascena Mill (rosa-de-damasco), Kazaz et al. (2010), também obtiveram resultados satisfatórios, com 100\% de germinação em casa vegetação. A ação de microrganismos do solo é citada em pelo menos 16 referências como importante fator de quebra de dormência exógena pela decomposição do envoltório das sementes dispostas sobre o solo.

Dentro dos tratamentos com diluições existiram variações. Nota-se que a ordem não foi crescente e proporcional nas concentrações, pois a proporção de 3\% (T3) de Bokashi teve resultado inferior relacionado proporção $2 \%$ (T2) porém T2 foi o que mais se aproximou do IE de 4\% (T4) Figura 7. 
Figura 7. Índice de Emergência dos Tratamentos as respectivas diluições.



Fonte: Dados da pesquisa.

Apesar dos resultados com EM apresentarem potencial de emergência em relação ao tratamento testemunha, ainda é necessário mais observações e estudo sobre o comportamento dos microrganismos em teste de germinação e pré-teste, concordando com Baskin \& Baskin (2000), que afirmam que há poucos resultados conclusivos que evidenciem como os EM agem e em qual mecanismo de dormência (endógena/exógena ou ambas) é eficaz.

Na Figura 8, observa-se a porcentagem de sementes emergentes, mortas e dormentes no teste de germinação, para cada tratamento. No T3 teve o maior percentual de mortes $23 \%$ e T2 teve o menor percentual $3 \%$ diferença de $20 \%$ entre os tratamentos, $\mathrm{T} 1$ e $\mathrm{T} 4$ tiveram percentual aproximados com 10\% e $12 \%$ respectivamente. Comparando os percentuais de emergência com o de sementes mortas o tratamento obteve o melhor saldo de E > M foi o T2 (23\%) seguido do T4(17\%), $\mathrm{T} 1(2 \%)$ e o que teve o pior resultado foi $\mathrm{T} 3$ com $6 \%$ de morte a mais que sementes germinadas.

Figura 8. Porcentagem de sementes emergentes, mortas e dormentes.

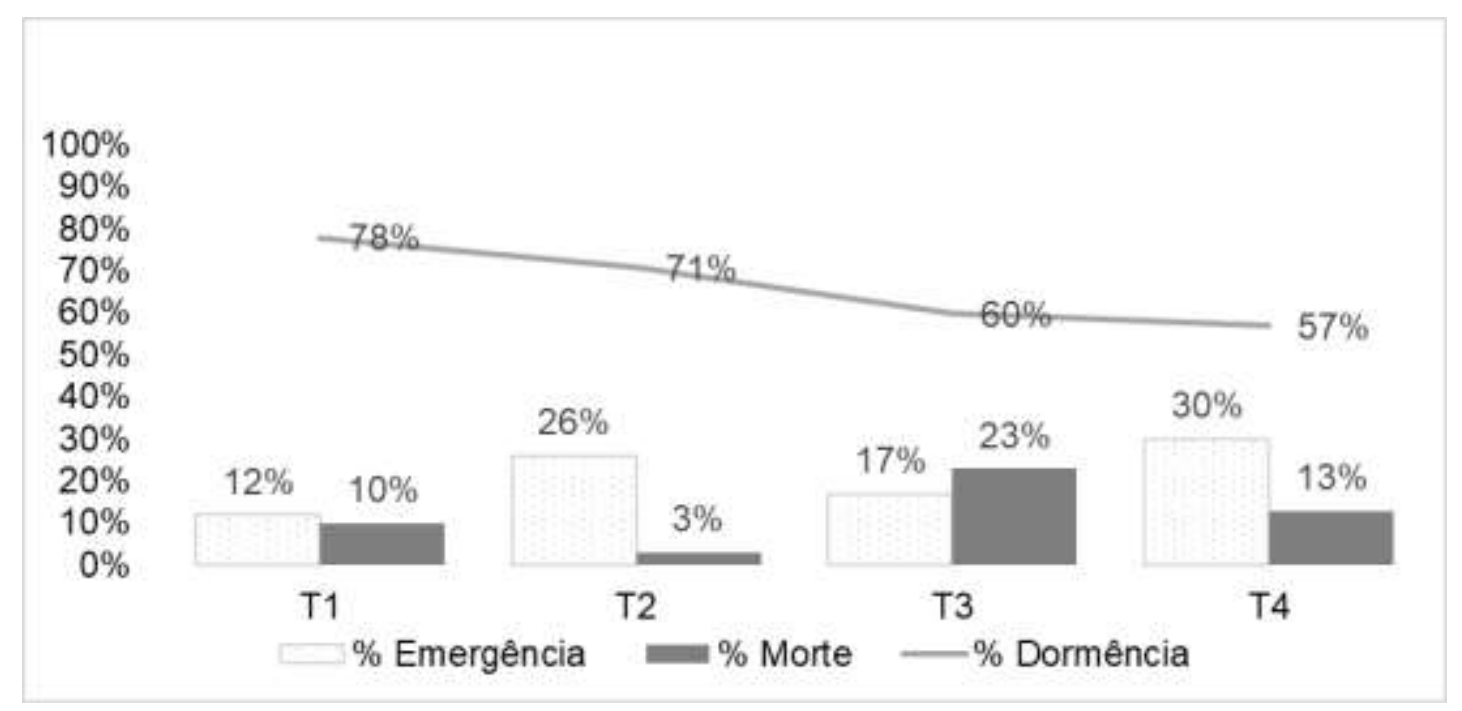

Fonte: Dados da pesquisa. 
A menor taxa de germinação observada no tratamento 3 e consequentemente grande percentual de morte das sementes provavelmente, pode ser provocada pelo intenso consumo de insetos da ordem Coleóptera na semente desta espécie (Souza et al., 2007), que provocou perda da capacidade germinativa das sementes. Esse fator pode ser determinante para diminuição da espécie, a grande predação de frutos em espécies da família Fabaceae, em ambientes tropicais, principalmente no cerrado e caatinga, é um fator preponderante para a queda no número final de frutos maduros (Zaidan et al., 2004) e consequente, na produção de sementes saudáveis.

\section{Considerações Finais}

As sementes de Canafístula semeadas em bokashi a 4\% obtiveram um bom índice de germinação e de velocidade de germinação. O tratamento que obteve melhor resultado foi o T4, seguido pelo T2 e o Tratamento 3 com bokashi a 3\% teve o maior índice de morte das sementes.

O experimento confirmou que é possível quebrar a dormência das sementes utilizando método de quebra com EM. As concentrações que se mostraram mais promissoras foram a $4 \%$ e $2 \%$, mas é possível estudar formas de melhorar ainda mais essa metodologia a fim de se ter um melhor desempenho no que se refere a porcentagem de sementes germinadas o que sugere novos trabalhos nessa temática. Várias pesquisas já demonstraram que a escarificarão química a mais eficiente na germinação de sementes dessa espécie em relação aos demais métodos.

\section{Agradecimentos}

Ao Grupo de Estudos Ambientais e Etnobiológicos -GEMBIO por todo o suporte na execução da pesquisa.

Ao Laboratório de Microbiologia Clínica e Experimental.

Á Universidade Estadual de Alagoas.

\section{Referências}

Albuquerque, K. S. et al. (2007). Métodos para a superação da dormência em sementes de sucupira-preta (Bowdichia virgilioides KUNTH). Ciência e agrotecnologia, 31(6), 1716-21.

Aragão, L. W., Mallmann, V. \& Silva, R. C. D. L. D. (2020). Bokashi: instrumento na Agroecologia e na produção agrícola sustentável. I Congresso Online Internacional de Sementes Crioulas e Agro biodiversidade, 4. Anais eletrônicos [...] 1-11.

Araujo, A. L. S. De. Pinheiro, R. A., Silva, A. M. Da., Araujo, A. Da S., Costa, M. L. A. Da., \& Barros, R. P. De. (2019). Nodulation of bacteria in crotalariajuncea (Crotalaria juncea L., fabaceae) and pigeon pea (Cajanus cajan (L.) Millsp., Fabaceae) crops with different sources of organic matter. Revista Ambientale, 11(3), 1-14. https://doi.org/10.48180/ambientale.v11i3.160.

Barbosa, J. C. \& Maldonado, J. W. (2011). Sistema para análise estatística de ensaios agronômicos. AgroEstat. Jaboticabal.

Baskin, J. \& Baskin, C. (2000). Evolutionary considerations of claims for physical dormancybreak by microbial action and abrasion by soil particles. Seed science research, pp. 409-13.

Bonfim, F. P.G et al. (2011). Caderno dos microrganismos eficientes (EM): instruções práticas sobre uso ecológico e social do EM (2 ed.). 32 p.

Brasil. Ministério Da Agricultura. (2009). Pecuária e Abastecimento. Regras para análise de sementes. MAPA/SDA.

Cardoso, V. J. M. (2009, dez). Conceito e classificação da dormência em sementes. Oecologia Brasiliensis, 13(4), 619-31.

Fowler, A. J. \& Bianchetti, A. (2000). Dormência em sementes florestais. Embrapa Florestas.

Kazaz, S. et al. (2010). Seed dormancy in oil rose (Rosa damascena Mill): By microbial inoculation. African Journal of Biotechnolohy, 6503-08.

Köppen, W. \& Geiger, R. (1928). Gotha. Wall-map. 150cmx200cm: Verlag Justus Perthes.

Leite, R. De. A. et al. (2021). Métodos de quebra de dormência em sementes de Umbuzeiro (Spondias tuberosa Arr. Cam.) (Anacardiaceae) para a produção de mudas. Research, Society and Development, [S. 1.]. 10(9), e13910917958. https://rsdjournal.org/index.php/rsd/article/view/17958.

Lopes, A. C. A. \& Nascimento, W. M. (2012). Dormência em sementes de hortaliças. Embrapa Hortaliças. Brasília. 28p. 
Research, Society and Development, v. 11, n. 1, e32011124989, 2022

(CC BY 4.0) | ISSN 2525-3409 | DOI: http://dx.doi.org/10.33448/rsd-v11i1.24989

Maia, G. N. (2004). Caatinga: árvores e arbustos e suas utilidades. 207f, 413p.

Moreira, A. \& Malavolta, E. (2004). Dinâmica da matéria orgânica e da biomassa microbiana em solo submetido a diferentes sistemas de manejo na Amazônia Ocidental. Pesquisa Agropecuária Brasileira, 1103-10.

Morpeth, D. R. \& Hall, A. (2000). Microbial enhancement of seed germination in Rosa corymbifera 'Laxa'. Seed Science Research, $10 \mathrm{v}, 489-94$.

Munhoz, R. E. F., Zonetti, P. C. \& Sidnei, R. (2009). Superação da dormência em sementes e desenvolvimento inicial em Brachiaria brizantha cv. MG-5 por meio da escarificação com ácido súlfurico. Revista em Agronegócios e Meio Ambiente, 2(1), 55-67.

Nunes, Y. R.F. et al. (2006). Germinação de sementes de Guazuma ulmifolia Lam. (Maslvaceae) e Heteropterys byrsonimifolia A. Juss (Malpighiaceae) sob diferentes tratamentos de escarificação tegumentar. Unimontes Científica. 8, 43-52.

Oliveira, F. N. et al. (2017). Germination and development of Simira gardneriana seedling. Revista Brasileira de Engenharia Agrícola e Ambiental. 21(5), 333-38.

Oliveira, L. M. De. et al. (2003). Avaliação de métodos para quebra de dormência e para desinfestação de sementes de canafístula (Peltophorum dubium (Sprengel) Taubert. Revista Arvore, 27(5), 597-603.

Piveta, G. (2010). Superação de dormência na qualidade de sementes e mudas: influência na produção de Senna multijuga (L. C. Rich.) Irwin \& Barneby. Acta Amazônica, 40(2), 281-88.

Santos, D. de S., Barros, R. P. de, Sousa, J. I. de, Galdino, W. de O, Silva, M. G. dos S, Araújo, A. da S, Silva, D. dos S, Lima, F. da S., Neves, J. D. dos S. das, \& Costa, J. G. da. (2021). Desenvolvimento inicial da fenologia da mamona (Ricinus communis L.) em diferentes substratos orgânicos. Research, Society and Development, 10(8), e14010817204. https://doi.org/10.33448/rsd-v10i8.17204

Silva, F. D. O. (2010). Constituintes químicos das folhas de Senna spectabilis (DC) Irwin e Barneby var. Excelsa (Schrad.) Irwin e Barneby. Química Nova, 33(9), 1874-76.

Siqueira, A. P. P. D. \& Siqueira, M. F. B. (2013). Bokashi: adubo orgânico fermentado. Programa Rio Rural. (40a ed).

Souza, S. C. A. et al. (2007). Biometria de frutos e predação de sementes de Senna spectabilis (DC) Irwin et Barn. (Fabaceae-Caesalpinioideae) provenientes de três localidades do norte de Minas Gerais. Revista Brasileira de Biociências, 5, 864-66.

Xavier, R. A. \& Dornellas, P. C. (2012). Caracterização ambiental do município de Arapiraca Região Agreste de Alagoas. Revista Ambientale. 1(3), 87-98.

Zaidan, L. \& Barbedo, C. Quebra de dormência em sementes. In: Ferreira, A. G., Borghetti, F. (2004). Germinação do básico ao aplicado. Artmed, $135-45$. 